\title{
Complications in multiple gestation pregnancy: A cross-sectional study of ten maternal-fetal medicine centers in China
}

\author{
Jun Wei ${ }^{1}$, Qi-Jun Wu ${ }^{2}$, Tie-Ning Zhang ${ }^{3}$, Zi-Qi Shen ${ }^{1}$, Hao Liu ${ }^{1}$, Dong-Ming Zheng ${ }^{1}$, \\ Hong Cui ${ }^{1}$, Collaborative Group on Twin Birth and Fetal Abnormality in China, Cai- \\ Xia Liu ${ }^{1}$ \\ ${ }^{1}$ Department of Obstetrics and Gynecology, Shengjing Hospital of China Medical University, Shenyang, China \\ ${ }^{2}$ Department of Clinical Epidemiology, Shengjing Hospital of China Medical University, Shenyang, China \\ ${ }^{3}$ Department of Pediatrics, Shengjing Hospital of China Medical University, Shenyang, China
}

Correspondence to: Cai-Xia Liu, e-mail: liucx1716@163.com

Keywords: China, cross-sectional study, multiple births, pregnancy complications

Received: January 10, 2016

Accepted: April 02, 2016

Published: April 26, 2016

\section{ABSTRACT}

Complications in women with multiple gestation pregnancy have not been studied in China. We aimed to establish a database of women with multiple gestation pregnancy and investigate the complications related to multiple pregnancy. We conducted a cross-sectional study that included 3246 women with multiple gestation pregnancy and who had multiple live-birth deliveries; the women were registered at ten maternal-fetal medicine centers in China in 2013. All participants completed a detailed questionnaire that included basic demographic information, history of gestation and abnormal fetal development, risk factors during pregnancy, and pregnancy outcomes. Overall, 1553 (47.8\%) women experienced pregnancy complications; these women were more likely to have lower height and less education than women who did not experience complications. However, women who experienced complications had a higher twin birth rate and were more likely to have received regular antenatal care and assisted reproductive technology than women without complications $(P<0.05)$. Notably, preterm birth was a primary complication in multiple pregnancy $(n=960)$. In conclusion, pregnancy complications, especially preterm birth, were relatively common in women with multiple gestation pregnancy. The findings from this crosssectional study in China may be used as a foundation for investigating risk factors for complications in women with multiple gestation pregnancy in the future.

\section{INTRODUCTION}

Multiple gestation pregnancies result from complex interactions among genetic and environmental factors. Hereditary influences, older maternal age, assisted reproductive technology (ART), and advanced parity are well-established risk factors for multiple pregnancy [1]. Multiple pregnancy and multiple live-birth rates have increased during recent decades and multiple births now account for $3 \%$ of all births worldwide [2-4]. The rate of twin birth increased by more than $75 \%$ in the United States from 1980 to 2009 [5]. Similar trends have been observed in Western Europe and other countries [4].

Nevertheless, multiple pregnancy is considered a high risk for obstetric complications such as spontaneous abortion, hypertensive disorders, placenta previa, and fetal malformations [6]. Specifically, the incidence of hypertensive disorders, a common source of maternal morbidity, is $15 \%$ to $35 \%$ in twin pregnancies, which is two to five times higher than in singleton pregnancies [7-12]. Additionally, the etiology of preterm birth is not completely understood, but the association between multiple pregnancy and preterm birth is well known [13]. A secondary analysis of the WHO Global Survey dataset indicated that $35.2 \%$ of multiple births were preterm ( $<37$ weeks gestation); of all multiple births, $6.1 \%$ of births were before 32 weeks gestation, $5.8 \%$ were during weeks 32 and 33, and 23.2\% were during weeks 34 through 37 [14]. Multiple-birth infants also have a substantially higher risk of perinatal mortality and, globally, multiple births account for $14 \%$ of all infant deaths [5]. 
The incidence of multiple birth in China is rising [15], but no recent studies have examined pregnancy complications in women with multiple pregnancy using a multi-center database. The two-child policy was established in China in 2016, so a baby-boom period is expected in the next decade and, with it, an increase in multiple gestation pregnancies. We conducted this cross-sectional study at ten hospitals in China to summarize complications in women with multiple pregnancy. We hope our findings will contribute to the establishment of diagnostic standards and treatments for complications of multiple pregnancy.

\section{RESULTS}

We included a total of 3246 women with multiple gestation pregnancy in our analysis. The majority of women delivered twins $(n=3101,95.5 \%)$. Table 1 presents the numbers of women with multiple pregnancy and pregnancy complications at each of the ten hospitals included in our database. Of these hospitals, the Women's Hospital School of Medicine at Zhejiang University had the most participants $(n=538,16.6 \%)$. The Shandong Provincial Hospital of Shandong University had the lowest proportion of twin births $(n=275,82.3 \%)$. The proportion of pregnancy complications varied among the ten hospitals; the Women's Hospital School of Medicine at Zhejiang University had the highest proportion of women with multiple pregnancy who experienced complications ( $n=457,84.9 \%$ ) and the Shanghai First Maternity and Infant Health Institute Affiliated Tongji University had the lowest proportion $(n=25,6.1 \%)$. The average proportion of pregnancy complications was $47.8 \%(n=1553)$ for all ten hospitals. Table 2 lists the numbers and types of pregnancy complications at each of the ten hospitals.

Table 3 presents the distribution of characteristics of women with multiple pregnancy with and without pregnancy complications. Women with complications had significantly lower height $(P=0.05)$ and education level $(P<0.01)$ than women without complications; however, women with complications had a higher rate of twin birth $(P=0.05)$ and were more likely to have received regular antenatal care $(P<0.05)$ and ART $(P<0.05)$.

Preterm birth was one of the primary complications of multiple pregnancy in our analysis (Table 4). In all, 960 women delivered preterm infants. Additionally, 341 women were diagnosed with gestational hypertension and 421 with gestational diabetes mellitus. Also, 334 women had pregnancies complicated by internal medicine, surgical, or infectious disease. These complications have significantly different characteristics from each other (data not shown).

\section{DISCUSSION}

Evidence of pregnancy complications in women with multiple gestation pregnancy is limited in China. To our knowledge, this is the first multi-center, cross-sectional study in China to describe complications in women with multiple pregnancy. Our findings indicate that women with pregnancy complications have lower height and education level but higher rates of twin birth, regular antenatal care, and ART than women without complications. Preterm birth was the most common pregnancy complication. The database from ten maternal-fetal centers could be used to investigate risk factors for complications in women with multiple pregnancy in the future.

In our analysis, 341 (9.95\%) women were diagnosed with gestational hypertension. This is consistent with the study by Ghulmiyyah et al. [16], which found that $8 \%$ to $10 \%$ of pregnant women worldwide experience gestational hypertension. Additionally, 421 (12.97\%) women were diagnosed with gestational diabetes. Hollander et al. [17] concluded that $2 \%$ to $10 \%$ of pregnancies, including multiple and singleton pregnancies, are affected by diabetes mellitus. The exact reason for the difference between Hollander's findings and ours is not clear, but it might be attributed to differences in populations, diets, and research methods. Further studies are warranted to confirm the rates of diabetes in pregnancy. In our study, $960(29.57 \%)$ women delivered preterm infants. The incidence of preterm delivery has been reported to be approximately $10 \%$ [18]. The higher rate observed in our study might result simply from the fact that we included only multiple pregnancies, which are frequently associated with preterm birth.

Little evidence of the effects of ART on maternal and fetal well-being is available [19]. Several metaanalyses and reviews have proposed that ART singleton pregnancies are associated with higher risks of adverse obstetric outcomes [20-23]. In our study, we found that the rate of pregnancy complications in women who received ART was significantly higher than in women who did not receive ART $(P<0.01)$. This finding was consistent with previous reports [24]. Specifically, Daniel et al. [25] found that women who received ART had higher incidences of pregnancy-induced hypertension, uterine bleeding, and fetal death than women who did not receive ART. We observed a possible link between ART and pregnancy complications, but further study is needed to confirm the association in women with multiple pregnancies and help obstetricians manage the risks associated with multiple pregnancy.

There are several strengths of this study. To our knowledge, this is the first cross-sectional study to assess the incidence of pregnancy complications in women with multiple pregnancy in China. We collected data from the ten largest maternal-fetal medicine centers in China in order to establish a national database for pregnancy complications in women with multiple pregnancy. All of the pregnancy complications were diagnosed by physicians and recorded through the hospital information systems. Since the information was not self-reported, we are confident in reporting results and drawing conclusions 
Table 1: The numbers of women with multiple gestation pregnancy and pregnancy complications at each of the ten hospitals

\begin{tabular}{|l|c|c|c|}
\hline \multicolumn{1}{c}{ Hospitals } & \multicolumn{1}{c}{$\begin{array}{c}\text { No. Multiples } \\
\text { births (\%) }\end{array}$} & $\begin{array}{c}\text { No. Twin } \\
\text { births (\%)* }\end{array}$ & \multicolumn{1}{c}{$\begin{array}{c}\text { No. pregnancy } \\
\text { complications (\%) }\end{array}$} \\
\hline First Affiliated Hospital of Chongqing Medical University & $180(5.5)$ & $177(98.3)$ & $71(39.4)$ \\
\hline First Affiliated Hospital of Sun Yat-sen University & $206(6.3)$ & $200(97.1)$ & $131(63.6)$ \\
\hline $\begin{array}{l}\text { Gulou Clinical Medical College of Nanjing Medical } \\
\text { University }\end{array}$ & $159(4.9)$ & $157(98.7)$ & $81(50.9)$ \\
\hline $\begin{array}{l}\text { Obstetrical and Gynecological Hospital affiliated Fudan } \\
\text { University }\end{array}$ & $468(14.4)$ & $461(98.5)$ & $180(38.5)$ \\
\hline Peking University First Hospital & $156(4.8)$ & $149(95.5)$ & $77(49.4)$ \\
\hline Shandong Provincial Hospital to Shandong University & $334(10.0)$ & $275(82.3)$ & $131(39.2)$ \\
\hline $\begin{array}{l}\text { Shanghai First Maternity and Infant Health Institute } \\
\text { Affiliated Tongji University }\end{array}$ & $409(12.6)$ & $408(99.8)$ & $25(6.1)$ \\
\hline Shengjing Hospital of China Medical University & $430(13.2)$ & $393(91.4)$ & $221(51.4)$ \\
\hline Third Hospital affiliated GuangZhou Medical University & $366(11.3)$ & $353(96.4)$ & $179(48.9)$ \\
\hline Women's Hospital School of Medicine Zhejiang University & $538(16.6)$ & $528(98.1)$ & $457(84.9)$ \\
\hline Overall & 3246 & $3101(95.5)$ & $1553(47.8)$ \\
\hline
\end{tabular}

*The proportions of twin births were calculated as the proportion of all multiples births at each hospital.

The proportions of pregnancy complications were calculated as the proportion of all multiples births at each hospital. Pregnancy complications included gestational hypertension, gestational diabetes mellitus, preterm birth, and pregnancy complicated with internal medicine, surgical, or infectious disease.

Table 2: The numbers of pregnancy complications at each of the ten hospitals

\begin{tabular}{|c|c|c|c|c|}
\hline Hospitals & $\begin{array}{c}\text { No. } \\
\text { Gestational } \\
\text { hypertension } \\
(\%)\end{array}$ & $\begin{array}{c}\text { No. } \\
\text { Gestational } \\
\text { DM }(\%)\end{array}$ & $\begin{array}{c}\text { No. } \\
\text { Preterm } \\
\text { birth (\%) }\end{array}$ & $\begin{array}{c}\text { No. Pregnancy } \\
\text { complicated with } \\
\text { internal medicine, } \\
\text { surgical, and } \\
\text { infectious disease }(\%)\end{array}$ \\
\hline $\begin{array}{l}\text { First Affiliated Hospital of Chongqing Medical } \\
\text { University }\end{array}$ & $16(4.7)$ & $30(7.1)$ & $26(2.7)$ & $10(3.0)$ \\
\hline First Affiliated Hospital of Sun Yat-sen University & $27(7.9)$ & $35(8.3)$ & $70(7.3)$ & $54(16.2)$ \\
\hline $\begin{array}{l}\text { Gulou Clinical Medical College of Nanjing Medical } \\
\text { University }\end{array}$ & $4(1.2)$ & $23(5.5)$ & $54(5.6)$ & $11(3.3)$ \\
\hline $\begin{array}{l}\text { Obstetrical and Gynecological Hospital affiliated } \\
\text { Fudan University }\end{array}$ & $65(19.1)$ & $60(14.3)$ & $66(6.9)$ & $23(6.9)$ \\
\hline Peking University First Hospital & $10(2.9)$ & $28(6.7)$ & $49(5.1)$ & $7(2.1)$ \\
\hline $\begin{array}{l}\text { Shandong Provincial Hospital to Shandong } \\
\text { University }\end{array}$ & $55(16.1)$ & $13(3.1)$ & $70(7.3)$ & $34(10.2)$ \\
\hline $\begin{array}{l}\text { Shanghai First Maternity and Infant Health Institute } \\
\text { Affiliated Tongji University }\end{array}$ & $11(3.2)$ & $18(4.3)$ & $0(0)$ & $0(0)$ \\
\hline Shengjing Hospital of China Medical University & $48(14.1)$ & $65(15.4)$ & $\begin{array}{c}124 \\
(12.9)\end{array}$ & $28(8.4)$ \\
\hline $\begin{array}{l}\text { Third Hospital affiliated GuangZhou Medical } \\
\text { University }\end{array}$ & $18(5.3)$ & $55(13.0)$ & $90(9.4)$ & $61(18.3)$ \\
\hline $\begin{array}{l}\text { Women's Hospital School of Medicine Zhejiang } \\
\text { University }\end{array}$ & $87(25.5)$ & $94(22.3)$ & $411(42.8)$ & $106(31.7)$ \\
\hline Overall & 341 & 421 & 960 & 334 \\
\hline
\end{tabular}


Table 3: Characteristics of women with multiple pregnancy with and without pregnancy complications

\begin{tabular}{|c|c|c|c|c|}
\hline Characteristic & Total & $\begin{array}{l}\text { Pregnancy with } \\
\text { complications* }\end{array}$ & $\begin{array}{l}\text { Pregnancy without } \\
\text { complications }\end{array}$ & $P$-value \\
\hline Number of women & 3246 & 1553 & 1693 & \\
\hline \multicolumn{5}{|l|}{ Mean (SD) } \\
\hline Age (years) & $30.2(7.0)$ & $30.2(4.5)$ & $30.0(4.3)$ & 0.17 \\
\hline Weight (kg) & $55.6(8.9)$ & $55.5(8.7)$ & $55.5(8.2)$ & 0.35 \\
\hline Height $(\mathrm{cm})$ & $161.2(5.4)$ & $160.7(4.9)$ & $161.3(5.0)$ & 0.05 \\
\hline \multicolumn{5}{|l|}{ No. (\%) } \\
\hline Twin births & 3101 (95.5) & $1498(96.5)$ & $1603(94.7)$ & 0.05 \\
\hline \multicolumn{5}{|l|}{ Education level } \\
\hline Above bachelor degree & $232(7.1)$ & $96(6.0)$ & $136(8.0)$ & $<0.01$ \\
\hline Alcohol drinking (yes) & $4(0.1)$ & $2(0.2)$ & $2(0.09)$ & 0.89 \\
\hline Cigarette smoking (yes) & $4(0.1)$ & $3(0.3)$ & $1(0.04)$ & 0.61 \\
\hline Regular antenatal care & $2129(65.6)$ & $1213(78.1)$ & $916(54.1)$ & $<0.05$ \\
\hline ART & $1574(48.5)$ & $788(50.7)$ & $786(46.4)$ & $<0.05$ \\
\hline IVF-ET & $1260(80.1)$ & $656(42.2)$ & $604(35.7)$ & \\
\hline Induction of ovulation & $196(12.5)$ & $87(5.6)$ & $109(6.4)$ & \\
\hline Artificial insemination and others & $118(7.5)$ & $45(5.7)$ & $73(9.3)$ & \\
\hline
\end{tabular}

ART, assisted reproductive technology; IVF-ET, in vitro fertilization and embryo transfer; SD, standard deviation.

*Pregnancy complications included gestational hypertension, gestational diabetes mellitus, preterm birth, and pregnancy complicated with internal medicine, surgical, or infectious disease.

Table 4: Characteristics of women with multiple pregnancy according to complications

\begin{tabular}{|c|c|c|c|c|}
\hline Characteristic & $\begin{array}{c}\text { Gestational } \\
\text { hypertension }\end{array}$ & $\begin{array}{c}\text { Gestational } \\
\text { DM }\end{array}$ & Preterm birth & $\begin{array}{l}\text { Pregnancy complicated with } \\
\text { internal medicine, surgical, } \\
\text { or infectious disease }\end{array}$ \\
\hline No. of cases & 341 & 421 & 960 & 334 \\
\hline \multicolumn{5}{|l|}{ Mean (SD) } \\
\hline Age (years) & $31.7(4.6)$ & $31.6(4.0)$ & $29.9(4.5)$ & $30.3(4.7)$ \\
\hline Weight (kg) & $56.4(8.0)$ & $57.2(9.7)$ & $54.9(8.5)$ & $55.5(8.3)$ \\
\hline Height $(\mathrm{cm})$ & $161.2(5.4)$ & $160.7(4.9)$ & $160.9(5.0)$ & $160.9(5.1)$ \\
\hline \multicolumn{5}{|l|}{ No. (\%) } \\
\hline Twin births & $326(95.6)$ & $410(97.4)$ & $925(96.4)$ & $320(95.8)$ \\
\hline \multicolumn{5}{|l|}{ Education level } \\
\hline Above bachelor degree & $241(70.7)$ & $238(56.5)$ & $51(5.3)$ & $219(65.6)$ \\
\hline Alcohol drinking (yes) & $2(0.6)$ & $2(0.5)$ & 0 & 0 \\
\hline Cigarette smoking (yes) & $4(1.2)$ & $3(0.7)$ & 0 & 0 \\
\hline Regular antenatal care & $235(68.9)$ & $346(82.2)$ & $801(83.4)$ & $261(78.1)$ \\
\hline ART & $164(48.1)$ & $243(57.7)$ & $467(48.6)$ & $173(51.8)$ \\
\hline IVF-ET & $140(85.4)$ & $212(87.2)$ & $389(83.3)$ & $143(82.7)$ \\
\hline Induction of ovulation & $21(12.8)$ & $20(8.2)$ & $57(12.2)$ & $21(12.1)$ \\
\hline Artificial insemination and others & $3(1.8)$ & $5(2.1)$ & $21(4.5)$ & $6(3.5)$ \\
\hline
\end{tabular}

ART, assisted reproductive technology; DM, diabetes mellitus; IVF-ET, in vitro fertilization and embryo transfer; SD, standard deviation. 
from the data. However, several limitations of our study should be considered. First, the study was a cross-sectional design. Unlike prospective studies, cross-sectional studies cannot examine etiologic objectives or confirm hypotheses. Additionally, cross-sectional studies often pose difficulty in determining the timing of events and they are associated with length-biased sampling. All of the hospitals included in our analysis were regional maternalfetal medicine centers, which made it difficult to conduct long follow-up of the women with multiple pregnancy after parturition. Further, although we collected data from the ten largest maternal-fetal medicine centers in China, Berkson's bias might appear in the study, which could overestimate the rates of pregnancy complications in twin births. Our findings should be interpreted with caution in pregnant women living in rural or less-developed areas.

In conclusion, the data from this cross-sectional study of women with multiple pregnancy in China may be used as baseline information not only to provide scientific evidence for the prevention and diagnosis of pregnancy complications but also to establish a population-based database of multiple pregnancies and births for health care and research purposes.

\section{MATERIALS AND METHODS}

\section{Study populations}

We performed a multi-center, cross-sectional study that analyzed women with multiple pregnancy in 2013. Each of the ten hospitals included in this study was a Grade 3 facility affiliated with a university. The hospitals were located in different regions of China, and they were among the first hospitals approved by the National Health and Family Planning Commission of the People's Republic of China to establish local regional maternalfetal medicine centers. The institutional review board of each facility approved our study. The ten hospitals were: First Affiliated Hospital of Sun Yat-sen University, First Affiliated Hospital of Chongqing Medical University, Gulou Clinical Medical College of Nanjing Medical University, Obstetrical and Gynecological Hospital Affiliated to Fudan University, Peking University First Hospital, Shandong Provincial Hospital of Shandong University, Shanghai First Maternity and Infant Health Institute Affiliated to Tongji University, Shengjing Hospital of China Medical University, Third Hospital Affiliated at GuangZhou Medical University, and Women's Hospital School of Medicine at Zhejiang University.

To be eligible for the study, women must have had a multiple gestation pregnancy, including normal twins and abnormal twins. Pregnant women who were diagnosed with a twin pregnancy by ultrasound in early pregnancy were also included. Women who were pregnant with fetuses with trisomy 21 , trisomy 18 , or trisomy 13 were not included in this study. In all, a total of 3246 women with multiple pregnancy from ten hospitals were included in the analysis; the response rate was $95.9 \%$.

\section{Exposure measurement}

We extracted data from a pre-existing database that contained various demographic and delivery information, including select obstetric and neonatal outcomes for all women who delivered at the hospitals. The data were entered by nurses or physicians who attended the deliveries; quarterly audits ensured the accuracy of data entry. Each woman included in our study provided informed consent, and nurses or physicians were then allowed to collect information from the hospital information system during a woman's hospitalization. When quality or completeness of the data was questionable, an in-person interview was conducted to complete the questionnaire. The questionnaire comprised the following four sections: 1) basic demographic information, 2) history of gestation and abnormal fetal development, 3) risk factors during pregnancy, and 4) pregnancy outcomes.

For example, we classified study participants as ever smokers or drinker if they had ever smoked cigarettes or drank alcohol. For women who received assisted reproductive technology, we also collected the method they received (in vitro fertilization and embryo transfer, induction of ovulation, and artificial insemination and others). The information of weight and height prior to give birth were collected during a woman's hospitalization.

\section{Outcomes assessments}

Pregnancy complications in women with multiple pregnancy included hypertensive disorders, gestational diabetes mellitus, preterm birth, pregnancy complicated with internal medicine disease, pregnancy complicated with surgical disease, and pregnancy complicated with infectious disease. The diagnostic criteria for hypertensive disorders in pregnancy included clinical diagnosis by an obstetrician during pregnancy and systolic/diastolic blood pressure greater than $140 / 90 \mathrm{mmHg}$ with or without proteinuria [26]. The diagnostic criteria for gestational diabetes mellitus included clinical diagnosis by an obstetrician during pregnancy and a 75-g oral glucose tolerance test that resulted in a fasting blood glucose level of greater than $5.1 \mathrm{mmol} / \mathrm{L}$, a 1-hour postprandial blood glucose level greater than $10.0 \mathrm{mmol} / \mathrm{L}$, or a 2-hour postprandial blood glucose level greater than $8.5 \mathrm{mmol} / \mathrm{L}$ [27]. The diagnostic criteria for preterm birth was delivery between 28 and 37 weeks gestation [28]. The diagnostic criteria for pregnancy complicated with internal medicine disease included clinical diagnosis by an obstetrician during pregnancy and physician-diagnosed disease of the cardiovascular system, respiratory system, digestive system, blood system, or any other body system. The 
diagnostic criteria for pregnancy complicated with surgical disease included clinical diagnosis by an obstetrician during pregnancy and surgeon-diagnosed gastrointestinal disease, orthopedic disease, trauma, or other surgical disease or complication. The diagnostic criteria for pregnancy complicated with infectious disease included clinical diagnosis by an obstetrician during pregnancy and diagnosis by an infectious diseases specialist of hepatitis, syphilis, AIDS, or other infectious disease.

\section{Statistical analyses}

We calculated the means and percentages of selected variables for pregnancies with and without complications. We compared the data using $t$-tests for continuous variables and Pearson $\chi^{2}$ tests for categorical variables. Statistical analyses were conducted using SPSS 16.0 (SPSS Institute, Chicago, Illinois, USA), and a two-sided $P$-value of 0.05 was considered statistically significant.

\section{ACKNOWLEDGMENTS}

JW, Q-JW, CGTBFA, and C-XL designed the research; JW, Q-JW, T-NZ, Z-QS, HL, CGTBFA, and C-XL conducted the research; JW, Q-JW, T-NZ, and Z-QS analyzed the data; and JW, Q-JW, T-NZ, Z-QS, HL, HC, and $\mathrm{C}-\mathrm{XL}$ wrote the draft of the manuscript. All of the authors read, reviewed, and approved the final manuscript. C-XL had primary responsibility for the manuscript's final content.

We are grateful to the members of the Collaborative Group on Twin Birth and Fetal Abnormality in China (CGTBFA), including the Women's Hospital School of Medicine Zhejiang University (Prof. Jing He), the Obstetrical and Gynecological Hospital affiliated Fudan University (Prof. Xiaotian Li), the Shanghai First Maternity and Infant Health Institute Affiliated Tongji University (Prof. Tao Duan), the Third Hospital affiliated Guangzhou Medical University (Prof. Dunjin Chen), the Shandong Provincial Hospital to Shandong University (Prof. Xietong Wang), the First Affiliated Hospital of Sun Yat-sen University (Prof. Zilian Wang), the First Affiliated Hospital of Chongqing Medical University (Prof. Hongbo Qi), the Peking University First Hospital (Prof. Huixia Yang) and the Gulou Clinical Medical College of Nanjing Medical University (Prof. Yali Hu).

\section{CONFLICTS OF INTEREST}

The authors have no competing financial interests to declare.

\section{GRANT SUPPORT}

This study was supported by grants from the China National Health and Family Planning Commission (No. 201402006 to $\mathrm{C}-\mathrm{XL}$ ) and the funding of the Obstetric
Diseases Translational Medicine Research Center Project of Liaoning Province (No.2014225007 to C-XL).

Qi-Jun $\mathrm{Wu}$ was supported by the Fogarty International Clinical Research Scholars and the Fellows Support Center at the Vanderbilt Institute for Global Health, funded by the Fogarty International Center of the National Institutes of Health through an R24 Training Grant (D43 TW008313 to Xiao-Ou Shu).

\section{REFERENCES}

1. Bortolus R, Parazzini F, Chatenoud L, Benzi G, Bianchi MM, Marini A. The epidemiology of multiple births. Hum Reprod Update. 1999; 5:179-187.

2. Pharoah PO, Glinianaia SV, Rankin J. Congenital anomalies in multiple births after early loss of a conceptus. Hum Reprod. 2009; 24:726-731.

3. Martin JA, Hamilton BE, Osterman MJ. Three decades of twin births in the United States, 1980-2009. NCHS Data Brief. 2012:1-8.

4. Pison G, D'Addato AV. Frequency of twin births in developed countries. Twin Res Hum Genet. 2006; 9:250-259.

5. Collins J. Global epidemiology of multiple birth. Reprod Biomed Online. 2007; 15 Suppl 3:45-52.

6. Choi SH, Park YS, Shim KS, Choi YS, Chang JY, Hahn WH, Bae CW. Recent trends in the incidence of multiple births and its consequences on perinatal problems in Korea. J Korean Med Sci. 2010; 25:1191-1196.

7. Sibai BM, Hauth J, Caritis S, Lindheimer MD, MacPherson C, Klebanoff M, VanDorsten JP, Landon M, Miodovnik M, Paul R, Meis P, Thurnau G, Dombrowski M, et al. Hypertensive disorders in twin versus singleton gestations. National Institute of Child Health and Human Development Network of Maternal-Fetal Medicine Units. Am J Obstet Gynecol. 2000; 182:938-942.

8. Coonrod DV, Hickok DE, Zhu K, Easterling TR, Daling JR. Risk factors for preeclampsia in twin pregnancies: a population-based cohort study. Obstet Gynecol. 1995; 85:645-650.

9. Krotz S, Fajardo J, Ghandi S, Patel A, Keith LG. Hypertensive disease in twin pregnancies: a review. Twin Res. 2002; 5:8-14.

10. Norwitz ER, Edusa V, Park JS. Maternal physiology and complications of multiple pregnancy. Semin Perinatol. 2005; 29:338-348.

11. Rao A, Sairam S, Shehata H. Obstetric complications of twin pregnancies. Best Pract Res Clin Obstet Gynaecol. 2004; 18:557-576.

12. Santema JG, Koppelaar I, Wallenburg HC. Hypertensive disorders in twin pregnancy. Eur J Obstet Gynecol Reprod Biol. 1995; 58:9-13.

13. Stock S, Norman J. Preterm and term labour in multiple pregnancies. Semin Fetal Neonatal Med. 2010; 15:336-341. 
14. Vogel JP, Torloni MR, Seuc A, Betran AP, Widmer M, Souza JP, Merialdi M. Maternal and perinatal outcomes of twin pregnancy in 23 low- and middle-income countries. PLoS One. 2013; 8:e70549.

15. Lu X, Zhang J, Liu Y, Wang T, Lu Y, Li Z. Epidemiology of twin births in southeast China: 1993-2005. Twin Res Hum Genet. 2013; 16:608-613.

16. Ghulmiyyah L, Sibai B. Maternal mortality from preeclampsia/eclampsia. Semin Perinatol. 2012; 36:56-59.

17. Hollander MH, Paarlberg KM, Huisjes AJ. Gestational diabetes: a review of the current literature and guidelines. Obstet Gynecol Surv. 2007; 62:125-136.

18. Rode L, Tabor A. Prevention of preterm delivery in twin pregnancy. Best Pract Res Clin Obstet Gynaecol. 2014; 28:273-283.

19. Ombelet W, Peeraer K, De Sutter P, Gerris J, Bosmans E, Martens G, Ruyssinck G, Defoort P, Molenberghs G, Gyselaers W. Perinatal outcome of ICSI pregnancies compared with a matched group of natural conception pregnancies in Flanders (Belgium): a cohort study. Reprod Biomed Online. 2005; 11:244-253.

20. Helmerhorst FM, Perquin DA, Donker D, Keirse MJ. Perinatal outcome of singletons and twins after assisted conception: a systematic review of controlled studies. BMJ. 2004; 328:261.

21. Qin J, Liu X, Sheng X, Wang H, Gao S. Assisted reproductive technology and the risk of pregnancyrelated complications and adverse pregnancy outcomes in singleton pregnancies: a meta-analysis of cohort studies. Fertil Steril. 2016; 105:73-85.e1-6. doi: 10.1016/j. fertnstert.2015.09.007.

22. Jackson RA, Gibson KA, Wu YW, Croughan MS. Perinatal outcomes in singletons following in vitro fertilization: a meta-analysis. Obstet Gynecol. 2004; 103:551-563.
23. McDonald SD, Murphy K, Beyene J, Ohlsson A. Perinatel outcomes of singleton pregnancies achieved by in vitro fertilization: a systematic review and meta-analysis. J Obstet Gynaecol Can. 2005; 27:449-459.

24. Bamberg C, Fotopoulou C, Neissner P, Slowinski T, Dudenhausen JW, Proquitte H, Buhrer C, Henrich W. Maternal characteristics and twin gestation outcomes over 10 years: impact of conception methods. Fertil Steril. 2012; 98:95-101.

25. Daniel Y, Ochshorn Y, Fait G, Geva E, Bar-Am A, Lessing JB. Analysis of 104 twin pregnancies conceived with assisted reproductive technologies and 193 spontaneously conceived twin pregnancies. Fertil Steril. 2000; 74:683-689.

26. Group of Obstetrics and Gynecology branch of Chinese Medical Association of hypertensive disorders in pregnancy. Guidelines for the diagnosis and treatment of hypertensive disorder complicating pregnancy (2015). Chin J Obstet Gynecol. 2015; 10:721-728.

27. Department of Obstetrics and Gynecology branch of study group of the Chinese Medical Association and Cooperative group of pregnancy complicated with diabetes mellitus in Chinese Medical Association. Guidelines for the diagnosis and treatment of pregnancy complicated with diabetes (2014). Chin J Obstet Gynecol. 2014; 8:561-569.

28. Department of Obstetrics and Gynecology branch of study group of the Chinese Medical Association. Guidelines for clinical diagnosis and treatment of preterm labor (2014). Chin J Obstet Gynecol. 2014; 7:481-485. 